\title{
Construction and Testing of Belt Conveyor System for Auchi Polytechnic Demonstration Farm
}

\author{
Okwudibe H. A. ${ }^{1} \quad$ Suleiman A. I. ${ }^{2} \quad$ Elemure Victoria Akewo ${ }^{3}$ \\ 1.Department of Mechanical Engineering Technology, Auchi Polytechnic Auchi, Edo State \\ 2.Department of Agricultural and Bio-Environmental Engineering Technology, Auchi Polytechnic Auchi, Edo \\ State \\ 3.Department of Civil Engineering Technology, Auchi Polytechnic Auchi
}

\begin{abstract}
Materials handling is a very important aspect of post-harvest operation, the socio-economic value and shelf life of crops especially perishables depends largely on how they are conveyed from one place to another, a conveyor is a mechanical handling equipment that moves materials from one location to another. Many kinds of conveying systems are available, and are used according to the various needs of different industries. The aim of this paper is to construct a belt conveyor machine for Auchi Polytechnic demonstration farm. This paper contains the design calculations and considerations of belt conveyor system, in terms of size, length, capacity and speed, roller diameter, power and tension, idler spacing, type of drive unit, diameter, location and arrangement of pulley, angle and axis of rotation, control mode, intended application. The completed work will help to reduce human effort and at the same time increase the productivity and accuracy levels that cannot be achieved with manual operations. Keywords: Materials handling, Post-harvest operations, Belt Conveyor, Frame, Material handling equipment, DOI: $10.7176 / \mathrm{JNSR} / 11-18-03$
\end{abstract}

Publication date:September $30^{\text {th }} 2020$

\section{INTRODUCTION}

Materials handling is defined as the art and science of conveying, elevating, positioning, transporting, packaging and storing materials. Materials handling is required in almost all human activities involving materials, but is mostly interrelated to industrial activities (Imran, 2011, Johanson, 2016). However, it is not considered a production process, since it does not add value to the final product. Hence, minimum costs for materials handling processes are targeted to allow for increased profits. Materials handling, generally, imply short distance movements of materials. Long travel movements are referred to as transportation of materials, where materials are transported by planes, barges, trains, etc. Loading and unloading of materials at the sources and destinations are usually included within the scope of materials handling (Bhandari, 2003, Daniyan et al., 2015). Materials handling is a very important aspect of post-harvest operation, the socio-economic value of crops especially perishables depends largely on how they are conveyed from one place to another by different conveyance system as shown in figure 1, conveyor systems allow quick and efficient transportation for a wide variety of materials, which make them very popular in the material handling and packaging industries. Many kinds of conveying systems are available, and are used according to the various needs of different industries (Vanamane et al., 2011). There are chain conveyors (floor and overhead) as well (Devendra and Mandloi, 2002). Chain conveyors consist of enclosed tracks, I-Beam, towline, power \& free, and hand pushed trolleys (Bhandari, 2003, Daniyan et al., 2015).

Conveyor systems are used widespread across a range of industries due to the numerous benefits they provide. Conveyor systems are commonly used in many industries, including the automotive, agricultural, computer, electronic, food processing, aerospace, pharmaceutical, chemical, bottling and canning, print finishing and packaging. Although a wide variety of materials can be conveyed, some of the most common include food items such as beans and nuts, bottles and cans, automotive components, scrap metal, pills and powders, wood and furniture and grain and animal feed (Aniket, 2015, Miss and Inamdar, 2011, Mulani, 2002, Ray, 2008). 


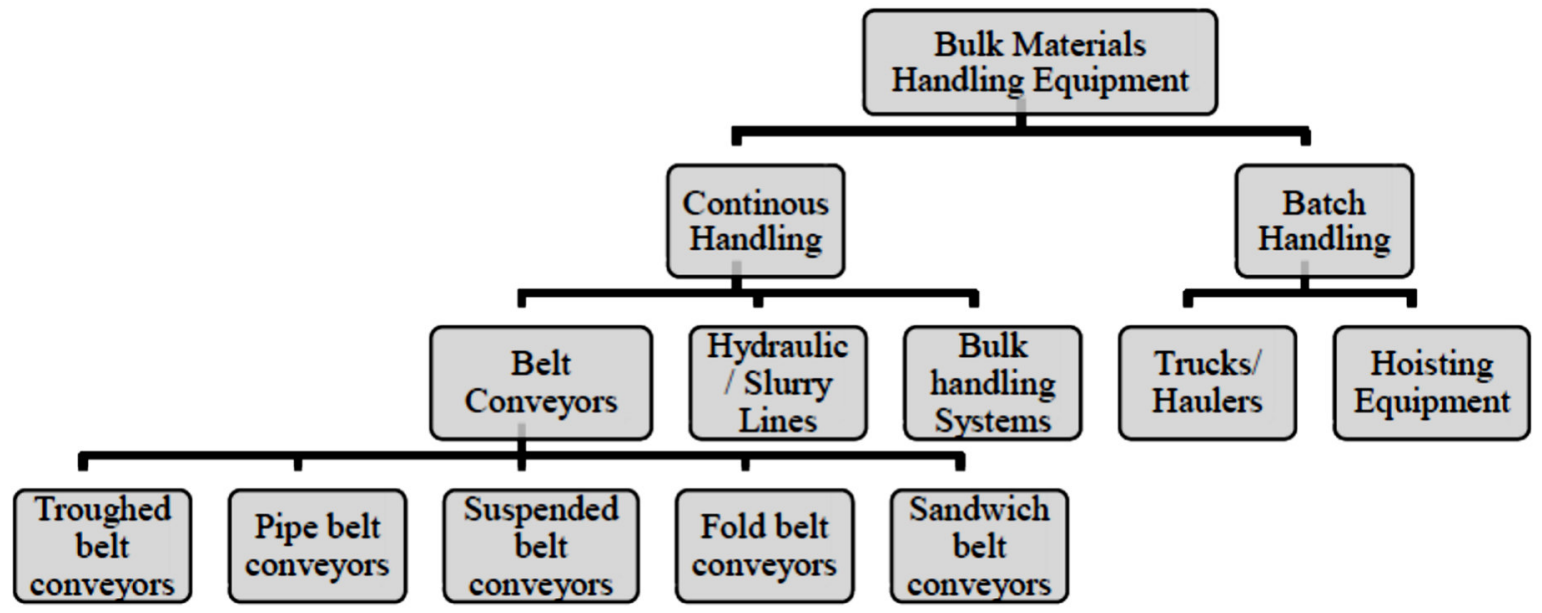

Figure 1: Classification of bulk materials handling equipment used in the mining industry Source: (Aniket, 2015)

Conveyors have many kind of benefits, it can almost can be installed anywhere. Besides, using conveyer as transportation to move load are much safer than using forklift or other machines. It also can move loads of all sizes and shapes. There are many types of conveyer machines such as gravity conveyer system, power belt conveyer systems, vibration conveyer systems, flexible conveyer systems and live roller conveyer system. The design capacity of the conveyor belt system was calculated from the information collected using different methods of calculation (Devendra and Mandloi, 2002). Three different methods of calculation were used to determine the design capacity of the conveyor belt system. The design of the belt conveyor must begin with an evaluation of the characteristics of the conveyed material and in particular the angle of repose and the angle of surcharge. The angle of repose of a material, also known as the "angle of natural friction" is the angle at which the material, when heaped freely onto a horizontal surface takes up to the horizontal plane (Bhandari, 2003, Daniyan et al., 2015).

The conveyer belt installations have been used for moving a wide variety of goods and materials for many decades. They continue to provide the fastest, safest, most effective and economical method of transportation over relative long distance often in areas where space is limited an operating under some of the most adverse conditions imaginable. The conveyer belt plays an integral role in the efficient operation of every conveyer system and has to be able to cope with an enormous variety of stresses and demands. Every conveying installation and the conditions that are required to operate in are of course different. This means that the correct choice of belt type and cover quality is crucial (Günthner and Rakitsch, 2010). There are several important technical rules, values and calculations involved when selecting a conveyer belt. This is also applies to installing new belts, so that they operate at maximum efficiency. A belt conveyor consists of an endless and flexible belt of high strength with two end pulleys (driver and driven) at fixed positions supported by rollers. In this work, roll idlers are required for adequate support of materials transported and protection of the belt along its length. Pulleys are used for providing the drive to the belt through a drive unit gear box powered by an electric motor. It also helps in maintaining the proper tension to the belt. The drive imparts power to one or more pulleys to move the belt and its loads (Bhandari, 2003, Daniyan et al., 2015).

Roller conveyor chains are generally used in production or assembly lines where individual large objects need to be conveyed. Roller conveyor chains differ from transmission roller chains such as a bicycle chain, which is used to transfer torque instead of conveying goods. Conveyor chains have a large pitch which is efficient in bridging large distances with fewer shackles, they generally have thicker side plates and rollers with large diameter (Günthner and Rakitsch, 2010). Therefore they can withstand higher tensile and shock loads than transmission chains. Furthermore they can bear large amounts of wear before breakage occurs.

Belt conveyors are used as the principle components of some complex machines such as wheel excavator, conveyor bridges and many other type of hoisting and conveying machines. Belt conveyors are used for various applications such as material transportation in foundry shop (supply and distribution of moulding sand, moulds and removal of wastes) coal and mining industry, sugar industry, automobile industry, Bagasse industry, fuel supply system of electric power stations etc (Vanamane et al., 2011, Vivek, 2013).

\section{MATERIALS AND METHODS}

The design of belt conveyor is depends upon design/construction of individual component, but the design of many individual component depends upon the ultimate design construction of belt conveyor. 


\section{Design Considerations}

The following requirements were taken into consideration in the design of the belt conveyor machine:

i. The availability of materials locally to reduce the costs of production and maintenance compared to imported machine;

ii. The strength of materials should be able to withstand the forces acting on the various component parts of the machine.

iii. It is desired that there should be minimum or no loss of the materials being conveyed.

iv. The materials selected for machine fabrication should not contaminate the agricultural materials being conveyed.

v. The machine should require minimum number of labour for operation and should also relief any fatigue during operation.

\section{Design parameter of a Belt Conveyor Machine}

The diameter of the driver and driven pulley is determined by the type and dimension of conveyor belting. The diameter of the pulley must be designed such that it does not place under stress on the belt. The length of a belt conveyor in metres is the length from the centre of pulley parallel to belt line. Belt length is dependent on both the pulley diameters and centre distances (Imran, 2011, Johanson, 2016).

Where:

$$
V=d \times 2 \pi \quad \text { Eq. } 1
$$

$\mathrm{V}=$ Belt speed;

$\mathrm{d}=$ diameters of rollers;

$\pi=\mathrm{pi}$

\section{Belt Capacity}

Capacity is the product of speed and belt cross sectional area Generally, belt capacity $(\mathrm{kg} / \mathrm{sec})$ is given as:

Where:

$$
\text { B. } C=3.6 \times A \times \rho \times V \quad \text { Eq. } 2
$$

$\mathrm{A}=$ belt sectional area $(\mathrm{m} 2)$;

$\rho=$ material density $(\mathrm{kg} / \mathrm{m} 3)$;

$\mathrm{V}=$ belt speed $(\mathrm{m} / \mathrm{s})$

\section{Conveyor Capacity}

The mass of material Mm (live load) per metre $(\mathrm{kg} / \mathrm{m})$ loaded on a belt conveyor is given as:

Where

$$
M m=C /(3.6 \times V) 50=C /(3.6 \times 1.5) \quad E q .3
$$

$\mathrm{C}=$ Conveyor capacity (tonnes/hr);

$\mathrm{V}=$ belt speed $(\mathrm{m} / \mathrm{s})$.

\section{Roller diameter}

The relationship between the maximum belt speed, roller diameter and the relative revolution per minute is given as:

Where

$$
n=\frac{(V \times 1000 \times 60)}{(d \times \pi)} \quad E q .4
$$

$\mathrm{n}=$ no of revolution per minute;

$\mathrm{d}=$ roller diameter $(\mathrm{mm})$;

$\mathrm{V}=$ belt speed $(\mathrm{m} / \mathrm{s})$

Belt basic length

Belt basic length $=2 \times$ (length along conveying route)

\section{Belt Power and Tensions}

The longer the length of the belt, the more the power required for the conveyor and the higher the vertical distance of the lift, the higher the magnitude of power required.

Power required driving the pulley

$$
P=(C \times L \times 3.75) / 1000 \quad E q .5
$$

The belt of the conveyor always experience tensile load due to the rotation of the electric drive, weight of the conveyed materials and due to the idlers. The belt tension must be great enough to prevent slippage between the drive pulley and the belt . 
Belt tension at steady state

Belt tension at steady state is given as:

$$
\begin{gathered}
T s s=1.37 \times \mu \times L \times g \times[2 \times M i+(2 \times M b+M m) \cos (\theta)] \\
+(H \times g \times M m)
\end{gathered}
$$

Where

Tss $=$ Belt tension at steady state $(\mathrm{N}) ;$

$\mu=$ Coefficient of friction (0.02)

$\mathrm{L}=$ Conveyor length $(\mathrm{m})$;

$\mathrm{g}=$ Acceleration due to gravity $(9.81 \mathrm{~m} / \mathrm{sec} 2)$;

$\mathrm{Mi}=$ Load due to the idlers $(50 \mathrm{~kg})$;

$\mathrm{Mb}=$ Load due to belt $(55.7 \mathrm{~kg})$;

$\mathrm{Mm}=$ Load due to conveyed materials $(50 \mathrm{~kg})$;

$\Theta=$ Inclination angle of the conveyor (0o); and

$\mathrm{H}=$ Vertical height of the conveyor $(0.7 \mathrm{~m})$.

\section{Belt Tension while starting}

During the start of the conveyor system, the tension in the belt will be much higher than the steady state. The belt tension while starting is

Where

$$
T s=T s s \times K s \quad E q .7
$$

$\mathrm{Ts}=$ Belt tension while starting $(\mathrm{N})$;

Tss $=$ Belt tension at the steady state $(\mathrm{KN})$;

$\mathrm{KS}=$ Start up factor(1.08) .

\section{The effective load $\mathrm{F}(\mathrm{N})$ is given as}

$$
F=\mu T \times g(M m+M b / 2)+\mu R \times g\left(\frac{M b}{2}+M i\right) \quad \text { Eq. } 8
$$

Where:

$\mu \mathrm{T}=$ Coefficient of friction with support rollers $(0.033)$;

$\mu \mathrm{R}=$ Coefficient of friction with skid plate $(.033)$;

$\mathrm{g}=$ Acceleration due to gravity $(9.81 \mathrm{~m} / \mathrm{s} 2)$;

$\mathrm{Mm}=$ Total load of conveyed materials $(50 \mathrm{~kg}) \mathrm{Mb}=$ Mass of belt $(55.7 \mathrm{~kg})$;

$\mathrm{Mi}=$ Mass of roll idlers $(50 \mathrm{~kg})$

\section{Minimum Motor Power}

The minimum motor power for sizing of the motor is

Where,

$$
P \min =\frac{P}{\eta} \quad \text { Eq.9 }
$$

$\mathrm{P}$ min=Minimum motor power $(\mathrm{kW})$;

$\mathrm{P}=$ Power at drive pulley $(\mathrm{kW})$;

$\eta=$ Efficiency of the reduction gear

\section{Torsional moment is given as}

$$
M t=0.5 \times d \times(F+\mu W g) \quad E q .10
$$

Where:

$\mathrm{d}=$ Diameter of pulley $(\mathrm{m})$;

$\mathrm{F}=\operatorname{Effective~load}(\mathrm{N})$;

$\mu=$ Coefficient of friction;

$\mathrm{W}=$ Weight of material and Belt $(\mathrm{kg} / \mathrm{m}) ; \mathrm{g}=$ Acceleration due to gravity $(\mathrm{m} / \mathrm{s} 2)$

\section{The cycle time of conveyor is given as}

$$
C_{t}=2 L / V \quad E q .11
$$

Where,

$$
\mathrm{L}=\text { Length of conveyor }(\mathrm{m}) ; \quad \mathrm{V}=\text { Belt speed }(\mathrm{m} / \mathrm{sec})
$$

\section{Shaft Design}

The shaft design consists primarily of determination of the correct shaft diameter that will ensure satisfactory rigidity and strength when the shaft is transmitting motion under different operating and loading conditions. The 
values of belt width and pulley diameter helps in selecting the size of shaft diameter from different conveyors hand book (Aniket, 2015).

\section{MANUFACTURING PROCESS OF COMPONENT PARTS}

i. Column: Based on the design, column is manufactured for size MC 200. After the manufacturing, the installation of belt conveyor system is done at manufacturing site.

ii. Drive Pulley: The pulley at the discharge end of conveyor may be either an idler or drive pulley. Usually has larger diameter than other pulley in the system and often lagged to increase the traction and pulley life (Aniket, 2015).

iii. $\quad$ Frame: Based on the design, frame is manufactured for size MC 200.

iv. Geared Motor and Gear Box: Based on the design, the motor speed $1500 \mathrm{rpm}$, power 10hp, diameter of shaft $138.24 \mathrm{~mm}$, diameter of pulley $636.10 \mathrm{~mm}$ geared motor and gear box are procured from the manufacturing organization.

v. Hold Down Pulley: It is also a nondrive pulley located after the pressure pulley, it helps to maintain the straightness of the belt during inclination for easy loading of material to be conveyed.

vi. Idlers: Idler is made up of mild steel material. For $1200 \mathrm{~mm}$ belt width, the idler diameter 139.7 is used.

vii. Pressure Pulley: It is non drive pulley located after the tail pulley on carrying side of the belt. Its primary function is to maintain the pressure.

viii. Pulley: Pulleys are necessary in conveyors to change the direction of belt in vertical planes and to form endless loop for continuous motion. Five types of pulleys are used, those are:

ix. Snub Pulley: This pulley mounted close to the drive pulley on return side of the belt the snubs pulleys primary job is to increase the angle of wrap around the drive pulley, thereby increasing traction its second purpose reducing belt tension which is important in maximizing conveyor component life (Sanket et al., 2015).

x. Tail Pulley: Tail Pulley a pulley at the tail of the belt conveyor opposite the normal discharge end; may be a drive pulley or an idler pulley. Tail pulleys are also useful in maintaining proper tension in the belt.

\section{RESULTS AND DISCUSSION}

The major components and its parameters in the conveyor system are finalized. The designed parameters are calculated by using standard practice. The belt width is $11.00 \mathrm{~m}$. The belt tension is $38 \mathrm{kN}$ The drive is having power of 10HP with $1500 \mathrm{rpm}$. The shaft and pulley diameters are 159 and $568 \mathrm{~mm}$ respectively. The spacing between the idler is 1 meter. By using the advanced control switches like pull cord switch, belt sway switch, zero speed switch one can control the motion, reduce the frequency of accidents in belt conveyor system. Plates $1-4$ in the appendix shows the final belt conveyor machine.

\section{CONCLUSION}

The conveyor system is successfully improvised using drive chain. The conveyor move without causing any slippage although the conveyor needs a regular maintenance to avoid any casualties in the future. This project also helps student to utilize their engineering information and improve the skill of student in solving the mechanical problems.

\section{CONFLICT OF INTERESTS}

The authors have not declared any conflict of interests.

\section{ACKNOWLEDGEMENTS}

The authors would like to thank the Managements of Tertiary Education Trust Fund (TETFUND) Abuja and Auchi Polytechnic, Auchi for providing the needed funding for this research work. This type of collaboration is crucial for sustainable development at the tertiary education level in Nigeria.

\section{REFERENCE}

Aniket A Jagtap (2015) "Design Of Material Handling Equipment:Belt Conveyor System For CrushedBiomass Wood Using V Merge Conveying System" Int. J. Mech. Engg. \& Rob. Res. 2015 ISSN 2278 - 0149

Bhandari V.B. (2003) "Design of Machine Element," Tata McGraw Hill publishing company, eighth edition (2003).

Daniyan I. A., A. O. Adeodu and O. M. Dada (2015)“Design of a Material Handling Equipment: Belt Conveyor System for Crushed Limestone Using 3 roll Idlers Journal Of Advancement In Engineering And Technology

Devendra Kumar, R.K. Mandloi (2002) “Analysis \& Prospects of Modification in Belt Conveyors” International Journal of Engineering Research and Applications (IJERA) ISSN: 2248-9622

Günthner W. A., C.T., S. Rakitsch (2010), Energy Efficiency in Bulk Materials Handling. bulk solids handling, 
2010. 30(3): p. 138 - 142.

Imran S. Khan (2011) “Study And Analysis Of Roller Conveyor In Material Handling” IJESRT ISSN: 2277-9655 (I2OR), Publication Impact Factor: 3.785

Johanson, J. (2016) “Bulk Material Engineering”. Available from: http://jenike.com/industry/environmental/.

Miss S. S. Vanamane and Dr. K. H. Inamdar, Design of Belt Conveyor System used for Cooling of Mould, International Conference on Sunrise Technologies (MS) 13-15 Jan 2011, pp ME294-ME298.

Mulani, I.G., Engineering Science and Application Design for Belt Conveyors. 2002, Pune, India: Madhu I. Mulani. Ray, S., Introduction to materials handling. 2008, New Delhi: New Age International Publishers.

Sanket Kolte, Rohit Khandre, U. V. Patil "Design And Manufacturing Methodology For Conveyor" International Journal of Science, Technology \& Management Volume No.04, Issue No. 05, May 2015 ISSN (online): 2394 1537

Vanamane S.S, Mane P. A and Dr. Inamdar K.H, Introduction to belt conveyor system used for cooling of mould, National Conference on Recent Advances in Manufacturing Engineering and Technology, Hyderabad, Jan 10-11, 2011. pp 104-108.

Vivek A. Bandebuche "Parts Handling Systems for Machine Shops of Small and Medium Enterprises" International Journal of Engineering Research and General Science Volume 1, Issue 2, December 2013 ISSN 2091-2730.

\section{APPENDIX}
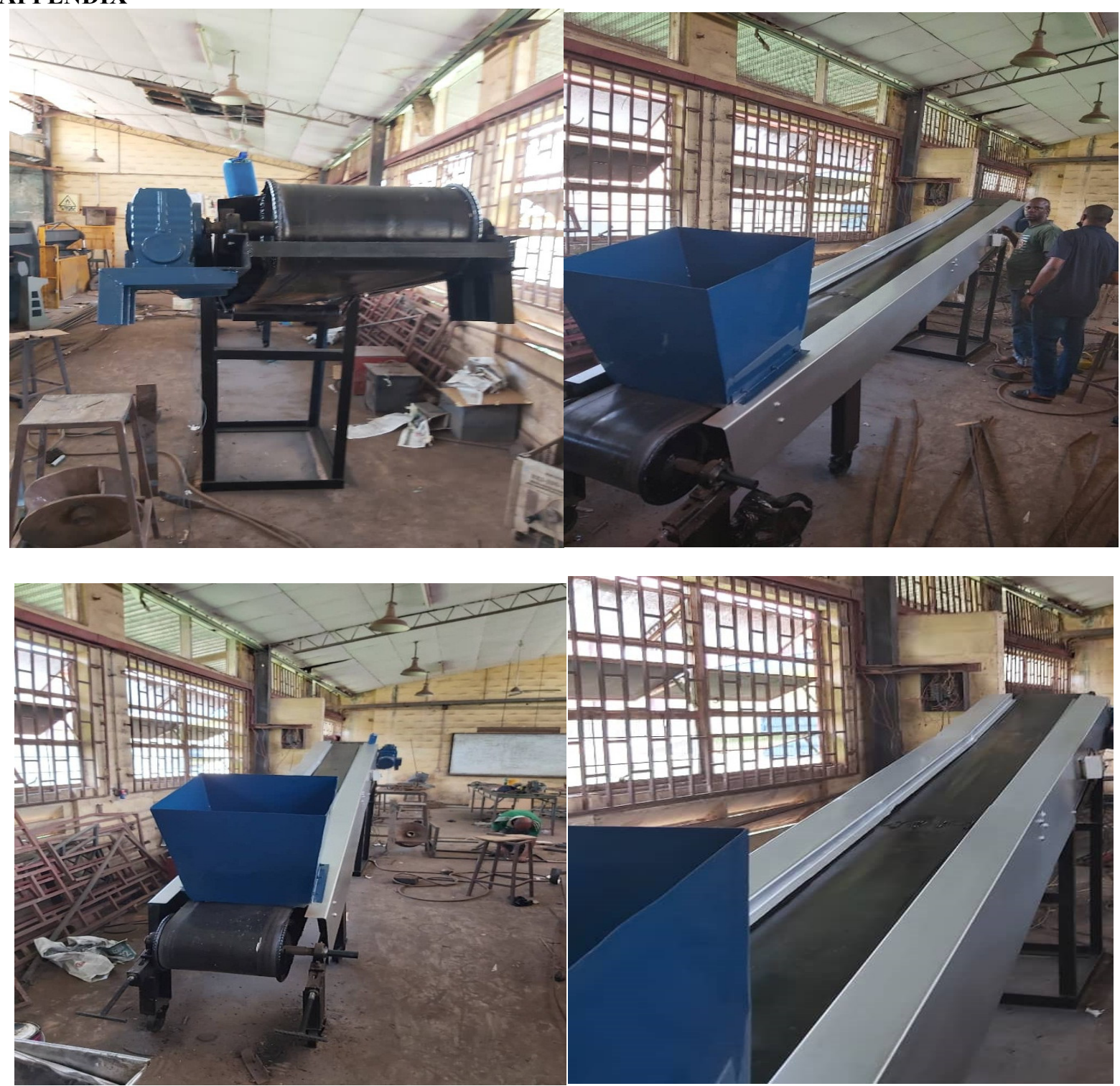

Plate 1 - 4: Completed Belt Conveyor 